\title{
COMPETING FOR RECOGNITION THROUGH PUBLIC GOOD PROVISION
}

\author{
MATTIAS POLBORN \\ CESIFO WORKING PAPER No. 1920 \\ CATEgory 1: Public Finance \\ FEBRUARY 2007
}

An electronic version of the paper may be downloaded

- from the SSRN website:

- from the RePEc website:

- from the CESifo website:

www.SSRN.com

www.RePEc.org

www.CESifo-group.de 


\title{
COMPETING FOR RECOGNITION THROUGH PUBLIC GOOD PROVISION
}

\begin{abstract}
Consider a setting in which several groups of individuals with common interests ("clubs") compete with each other for recognition by other individuals. Depending on the context, recognition may be expressed by these other individuals joining a club, or choosing one club to admire. Clubs compete by providing a public good. Some examples for applications of this model include: (i) Churches missionarizing to attract new members; (ii) Open-source software projects and Wikipedia; (iii) professors of an economics department competing to attract graduate students to their respective fields; (iv) artists and researchers aiming for recognition of their work by their peers and the public. Competition between clubs increases the public good provision level, and a sufficiently strong competition effect may even lead to overprovision.
\end{abstract}

JEL Code: H41.

Keywords: public goods, private provision, clubs, competition.

\author{
Mattias Polborn \\ Department of Economics \\ University of Illinois \\ 1206 South $6^{\text {th }}$ Street \\ Champaign, IL 61820 \\ USA \\ polborn@uiuc.edu
}

This version: January 21, 2007

First version: July 2006

I would like to thank Brad Humphreys, Kai Konrad and Matthias Messner for very helpful comments. 


\section{Introduction}

One of the fundamental results of public economics is that public goods are underprovided relative to the social optimum, if the provision decision is not centralized, but rather left to the voluntary contributions of economic agents. This market failure explains why most public goods are state provided.

Yet, there are several areas in which the private provision of public goods has been remarkably successful. Linux and Latex, Firefox and Thunderbird are just some examples of the success of open-source software projects, where the program code is essentially a public good provided by volunteers. A related example is the online encyclopedia Wikipedia, in which thousands of contributors cooperate to provide an information source of remarkably high quality. ${ }^{1}$

While these projects are prime examples of the successful private provision of public goods, existing economic models of the private provision of public goods do not appear to match these applications very well. In particular, in Bergstrom, Blume, and Varian (1986), economic agents are motivated to contribute to the public good by the fact that they also consume it and benefit from a higher provision level. While this incentive is, of course, insufficient from a social point of view, as it ignores the positive externalities imposed on other players, it at least provides some motivation for players. ${ }^{2}$

However, this consideration cannot explain at all why people donate time to Wikipedia: An individual who can write a lexicon article on a subject does not need that article for himself and consequently the existence of this public good should not affect his utility at all. Therefore, something else must motivate Wikipedia contributors. Similarly, contributors to Latex or Linux open source software projects could choose just to write the extension packages that are useful to them without making them available as public goods. Posting packages requires writing considerable documentation (in order that other people can use the package and possibly modify it later on), so choosing to make one's own package a public good involves considerable effort cost while not improving the "quality" of the package for the purpose of the author's own consumption.

Similarly, many professors outside North America (or even there, when they are close to their retirement) have minimal financial incentives to publish their research, or none at all. However, some continue to spend lots of energy for that purpose and are thus private suppliers of public goods. Again, if these professors were motivated only by the desire to

\footnotetext{
${ }^{1}$ For example, a recent study by the science journal Nature of 42 articles in Wikipedia and (the commercial leader) Encyclopedia Britannica found that the number of factual mistakes was essentially the same for both sources. See Giles (2005).

${ }^{2}$ There are other models of the incentives for private provision of public goods. These are reviewed in the next subsection.
} 
gain knowledge for their own consumption, it is hard to see why they should bother with any additional work generated by publishing their research.

It appears plausible that the main motivation for the public good contributors in the examples above (and in many other cases) is that they enjoy that other people use "their" work or are attracted to the subjects that the original contributors find attractive. Depending on the situation, there may be several ultimate reasons why public good contributors enjoy attracting other people. For example, one of the main motivation of open source software contributors is probably the recognition of their work by their peers and the users of their program. The more skillfully a program extension is written, the more people will use that extension and the higher is its author's reputation gain. It is plausible that an analogous motivation is also important for many researchers.

Perens (2005) suggests that free-riding behavior is not a major problem for open-source software projects: ${ }^{3}$ "All Open Source users start out as free-riders. They download and try the software, and perhaps deploy it, and do not generally consider contributing to that software's development until they are already using it and desire an additional feature. [...] Volunteers derive emotional fulfillment from having users for their software, just as artists derive fulfillment from having others appreciate their paintings. For volunteers, users provide an intangible benefit which the volunteer desires. Thus, those users should not be considered free-riders."

In the Wikipedia example, contributors may enjoy other people becoming better informed on a subject that is close to the heart of the contributor. In the field of religion, many church members engage in activities with the objective of attracting new believers to their creed. Similarly, professors in, say, microeconomics, may enjoy it if a gifted graduate student chooses to write his thesis in microeconomics, rather than going over to the dark side and specialize in macro or labor economics. And professors in those other fields are said to harbor analogous feelings.

In our model, public good providers are organized in "clubs". 4 There are two types of individuals, (old) club members and (new) potential members. Clubs provide a public good for their old members and for those individuals from the set of potential new members that decide to join a particular club. (When we call the action of the new players "joining", we have the religious or graduate student example above in mind; in the research or open source examples, "joining" should be thought of as a user or reader "paying his respect" to the author.)

\footnotetext{
${ }^{3}$ Bruce Perens is a prominent figure in the open source movement. He is a former Debian GNU/Linux Project Leader and co-founder of the Open Source Initiative.

${ }^{4}$ In some examples above, these clubs may contain only one member each. This is particularly the case when the ultimate reason for public good provision is the desire to become "famous". However, in other applications, several members have joint interests.
} 
Potential new members are attracted to clubs through the quality of public goods that the clubs provide, respectively. While an old member may or may not enjoy the public good by itself, he (also) receives utility when new players choose to join his club. We analyze the equilibrium in two scenarios: First, when individual club members decide how much to contribute to the public good; and second, when clubs are centralized and the contribution decision is made to maximize the utility of old club members. Equilibrium contributions are higher in the second scenario, and may be higher than socially optimal in both scenarios. Apart from the standard positive externality that contributors within one club exert on each other and on new members, there is also a negative externality between contributors in different clubs. The reason for this is that different clubs compete with each other for potential new members.

\section{$1.1 \quad$ Related literature}

The existing literature analyzing the private provision of public goods is divided into four branches. In one branch, pioneered by Bergstrom, Blume, and Varian (1986), individuals are motivated to contribute because they are consumers of the public good. In contrast, as explained above, individuals in our model are not (only) motivated to contribute in their role as consumers of the public good, but (also) because they aim for recognition by an audience.

Second, individuals may contribute to public goods because they are altruistic. Becker (1974) analyzes a model in which the "head of household" has the utility of other "household members" as arguments in his utility function. This framework is most plausible as a model of intrafamily behavior, while it might be a stretch to apply it to some of the examples above. ${ }^{5}$

Andreoni $(1989,1990)$ develops the third branch in which individuals are motivated to contribute by "impure altruism". While they do not necessarily care about the utility level that other individuals reach, they directly enjoy a "warm glow" when they give. Technically, the amount that an individual contributes is an argument of his utility function. In all three types of models covered so far, all players contribute to the same public good and enjoy it (or are at most indifferent), if other players increase their contribution level. In this sense, different players don't compete with each other, as they do in our model. As

\footnotetext{
${ }^{5} \mathrm{~A}$ paper related to both the first and second approach, and to our paper in that it models competition between different public good providers, is Peters and Siow (2002) who study premarital parental investments in children's wealth. In their model, parents care about their own children's utility. Spousal wealth is a public good in marriage, and more wealthy children can marry better spouses (spouse quality also affects utility). Like club members in our model, parents compete through providing a public good, and, as in our model, this competition with other families increases the equilibrium provision of the public good.
} 
a consequence, a player's optimal contribution level decreases, if the contribution level of other individuals increases. In contrast, players in our model create positive externalities for the audience they are trying to attract, but negative externalities on members of other clubs who compete for the same audience. Also, increased competition in our model (say, an increase in the number of clubs) may well lead to a a higher provision level by each club.

A fourth branch, which is probably most closely related to our paper, was pioneered by Glazer and Konrad (1996). In their model, players care about how wealthy they are perceived by other individuals, and use observable charity contributions to signal their wealth. This model therefore, like ours, builds on the notion that individuals contribute to public goods in order to impress their fellow citizens. However, contributors do not directly compete with each other in Glazer and Konrad, in the sense that the recognition that an individual gets who gives at least the equilibrium threshold contribution is not diminished, if there are also other individuals who contribute to charity. Also, players contribute to a single public good in Glazer and Konrad, while in our model, individuals in the same club cooperate through their contributions, while those in different clubs compete with each other.

Glazer and Konrad also show that a tax on contributions (rather than the subsidy commonly extended by the tax code through the deductibility of charitable donations) is beneficial in order to reduce signaling. ${ }^{6}$ This corresponds to our result that, if competition between clubs is sufficiently intense, the level of public good supplied may be excessive.

A paper related to the signaling branch is Benabou and Tirole (2006), who analyze a model in which an agent is motivated to exercise "pro-social behavior" (for example, public good provision) not only by his direct personal benefit from that action, but also by the respect his action generates from other people. Specifically, there is asymmetric information about the agent's preference type, and he receives a reputational utility if other people believe that he is "pro-social" (i.e., intrinsically enjoys providing the public good) and "not greedy" (i.e., has a low marginal utility of money). Public good provision is used to signal a favorable type. Our paper shares with Benabou and Tirole (2006) the feature that an agent is motivated to provide public goods through the respect his actions generate from fellow citizens. However, while they analyze a one-agent framework (or, one in which the reputational utility of different agents is independent of each other), in our model, agents compete with each other for the respect of their fellow citizens, which generates a negative externality between public good providers.

More peripherally, the present paper is also related to the literature on clubs and

\footnotetext{
${ }^{6}$ A similar result in a related framework is also derived in Blumkin and Sadka (2006).
} 
local public goods. ${ }^{7}$ A literature starting with Buchanan (1965) studies the formation of clubs in a framework in which players care about the number or identity of other club members. The main trade-off concerning club size is that adding members allows more cost sharing, but reduces the service quality experienced by all users. In the literature on local public goods, pioneered by Tiebout (1956), individuals "vote with their feet" to selfselect into one of many localities, and public good provision in each locality is determined by majority voting. Since sorting leads to (relatively) homogenous communities, majority voting implements (approximately) efficient levels of public good provision. Our paper shares with this literature the concept of free mobility, at least for potential new members.

\section{The model}

Each of $n$ different clubs has initially $M$ members. Furthermore, there are $P$ potential new members who can choose which club to join. To attract new members, and possibly for their own consumption, clubs or club members provide a public good $G$, which is produced from individual member contributions ( $e$, for effort). Specifically, we assume that club $j$ 's public good satisfies

$$
G_{j}=\sum_{i} e_{j}^{i}
$$

where $e_{j}^{i}$ is the contribution of the $i$ th member of club $j$, which costs that member $c\left(e_{j}^{i}\right)$. We assume that the cost function satisfies $c^{\prime}(0)=0$ and $c^{\prime \prime}(x)>0$ for all $x$.

Each club, and each potential new member, has a location on a circle with unit circumference. If potential new member $k$ joins club $j$, he receives a utility of

$$
A+G_{j}-\tau\left\|x_{k}-X_{j}\right\|
$$

where $x_{k}$ is the location of individual $k, X_{j}$ is the location of club $j$, so that $\left\|x_{k}-X_{j}\right\|$ is the distance between $x_{k}$ and $X_{j},{ }^{8}$ and $\tau$ is a "transportation cost" parameter. Intuitively, the clubs produce differentiated goods, and the distance between a club and a potential new member measures the ex-ante affinity of such a match (disregarding the quality of the public good provided). ${ }^{9}$ Each potential new member has an outside utility level of zero and either joins the club that provides him with the highest positive utility, or remains outside, if no club provides a positive utility.

\footnotetext{
${ }^{7}$ See Scotchmer (2002) for a review of this literature.

${ }^{8}$ Note that, for example, the shortest distance between points 0.1 and 0.9 on the circle is 0.2 (i.e., the distance along the way going over point 0 ).

${ }^{9}$ For example, consider different religious congregations competing with each other for new members. Each congregation is characterized by a fixed doctrine, which is likely to appeal differently to different potential new members, and by the level of community activities of the congregation, i.e., the public good $G_{j}$ in the language of our model.
} 
Clubs are spaced equidistantly on the circle, so that $X_{1}=0, X_{2}=1 / n, \ldots, X_{n}=$ $(n-1) / n$. Each of the $P$ new individuals' location is independently drawn from a uniform distribution on the circle. While each individual knows the realization of his own location, clubs know only the distribution from which they are drawn. ${ }^{10}$

The parameter $A$ allows us to distinguish cases in which the potential new members get a significant utility from joining some club from situations in which they might not join any club at all. ${ }^{11}$ Varying $A$ allows us to distinguish the effect on public good provision that arises from a preference for attracting new members alone, on the one hand, from the effect of competition between different clubs on the other hand.

Old club members receive utility from the level of the public good provided by their own club and from the number of new members who join their club, $P_{j}$. Specifically, the utility of member $i$ of club $j$ is

$$
U_{j}^{i}=\alpha G_{j}+(1-\alpha) P_{j}-c\left(e_{j}^{i}\right)
$$

where $\alpha \in[0,1]$ measures the weight that old members place directly on the public good supply, while $(1-\alpha)$ is the weight of the objective of attracting new members. (The linear form is chosen only to simplify notation, and all results would go through with a utility function $u(G, P)$ that is concave.

Interpretation The model fits best the church and graduate student examples from the introduction, because potential new members join (at most) one of the existing clubs. In other applications where public good providers crave for recognition (like the open source software example, artists, sports teams), audience members are in principle not limited to using only one OSS program, admiring only one artist, or to be a fan of only one club. However, empirical observation suggests that most people in the audience choose to engage in only a very limited number of such activities. Hence, providers compete with each other in these applications, too, and the general economic effects identified in the next section apply to these examples as well.

\footnotetext{
${ }^{10}$ The uncertainty over individual locations "smoothes" the model. If individual locations were known, then a club would have a very strong incentive to provide more of the public good if a potential new member is (almost) indifferent between the club and one of its competitors, and the same is, of course, true for the competing club. As a consequence, a model with known individual locations has the disadvantage (apart from using a less realistic assumption) that no pure strategy equilibrium exists.

${ }^{11}$ As an example for the first case, think of the graduate student example from the introduction, where students must write a thesis in one of the fields micro, macro or econometrics and cannot remain "fieldless" (unless they exit the program altogether). In this case, $A$ is large. As a different extreme, think of political parties; in most countries, only a small minority of eligible voters become party members, while the large majority remains without party affiliation.
} 


\section{Equilibrium}

We look at two scenarios for how the public good is provided. In the first one, each old member individually decides how much effort to contribute. In the second one, members in a club behave cooperatively; one can think of a club president who maximizes the utility of the initial club members, or club members who interact repeatedly and can "punish" other club members who play non-cooperatively. We compare the equilibrium in both scenarios with the social optimum.

In what follows, we look for a symmetric equilibrium in which all old members contribute the same amount to their club's public good. Consequently, in equilibrium, the amount of public good provided is the same for all clubs.

Decision to join a club. We first analyze the decision of a potential new member located at $x \in[0,1 / n]$ which club, if any, to join. We consider here the case that all types of potential new members join clubs in equilibrium. ${ }^{12}$ The individual is indifferent between clubs 1 and 2 (located at 0 and $1 / n$, respectively), if $A+G_{1}-\tau x=A+G_{2}-\tau\left(\frac{1}{n}-x\right)$, which we can solve for $x=\frac{1}{2 n}+\frac{G_{1}-G_{2}}{2 \tau}$. Similarly, one can compute the indifferent individual located between clubs $n$ and 1 . If both neighboring clubs provide a public good level of $\bar{G}$, the expected number of people who join club 1 is therefore

$$
P_{1}=P\left(\frac{1}{n}+\frac{G_{1}-\bar{G}}{\tau}\right) .
$$

The effect of an increase in $G_{1}$ on the expected number of people who will join the club is therefore

$$
\frac{d P_{1}}{d G_{1}}=P / \tau
$$

Social optimum. Consider a social planner who maximizes the aggregate sum of utilities of all individuals. The social planner chooses each old member's level of $e$ so as to maximize $^{13}$

$$
\max _{e} n M\left[\alpha M e+(1-\alpha) \frac{P}{n}-c(e)\right]+P\left[A+M e-\frac{\tau}{4 n}\right] .
$$

There are $n \cdot M$ old members, and if each of them provides effort $e$, each club produces $G=M e$ and attracts, in expectation, $P / n$ new members, so that each old member receives utility $\alpha M e+(1-\alpha) \frac{P}{n}-c(e)$. In expectation, each of the $P$ new members is a distance $1 / 4 n$ away from the club that he joins, so new members on average receive utility $A+M e-\frac{\tau}{4 n}$.

\footnotetext{
${ }^{12}$ We discuss further below the case that some potential new members might not join.

${ }^{13}$ Note that the maximization problem pre-supposes that it is optimal that each old member provides the same effort level, which is an obvious consequence of the convexity of the cost function and the concavity of each member's utility function.
} 
Taking the derivative with respect to $e$ yields the first-order condition

$$
n M^{2} \alpha-n M c^{\prime}(e)+P M=0
$$

Since the second derivative is $-n M c^{\prime \prime}(e)<0$, the first-order condition is necessary and sufficient for a maximum of the social planner's problem. Rearranging (7) slightly, we get

$$
\left(M \alpha+\frac{P}{n}\right) d e=c^{\prime}(e) d e .
$$

The left-hand side consists of the social benefit of a marginal increase of one old member's effort by de: Each of the $M$ club members benefits by $\alpha d e$; furthermore, each of the (on average) $P / n$ new members benefits by $d e$. This marginal social benefit of effort must be equal to the marginal cost of effort on the right hand side.

Note that the effect of public good provision on the joining decision of potential new members does not enter the optimal rule of the social planner. The reason is that any marginal rearrangement of new members does not change the sum of the utilities of old members, because the total number of new members for all clubs is fixed.

Public good provision by individual members. Consider now a situation in which each old club member decides individually how much of the public good to contribute. This is, for example, a reasonable model of an open source software project where there is no central authority that could enforce a higher level of contribution from members.

Member $i$ of club $j$ maximizes

$$
\alpha\left(e_{j}^{i}+\sum_{k \neq i} e_{k}^{j}\right)+(1-\alpha) P\left(\frac{1}{n}+\frac{e_{j}^{i}+\sum_{k \neq i} e_{k}^{j}-\bar{G}}{\tau}\right)-c\left(e_{j}^{i}\right) .
$$

Taking the derivative with respect to $e_{j}^{i}$ yields

$$
\alpha+(1-\alpha) \frac{P}{\tau}-c^{\prime}\left(e_{j}^{i}\right)=0
$$

Comparing (10) with (8) yields that the equilibrium level of effort is higher than the socially optimal level if

$$
\alpha(M-1)+\frac{P}{n}-(1-\alpha) \frac{P}{\tau}=\alpha\left(M-1+\frac{P}{\tau}\right)-\left(\frac{1}{\tau}-\frac{1}{n}\right) P<0,
$$

and lower than socially optimal if the inequality is reversed. A decrease of $\alpha$ or $\tau$, or an increase of $n$ make it more likely that (11) is satisfied. A low $\alpha$ means that individuals care primarily about attracting new members. An increase in the number of competing clubs, $n$, or a decrease in $\tau$ (making clubs better substitutes for new members) both intensify competition between clubs. For example, if $\alpha=0$, the condition for old members to 
provide too much of the public good boils down to $\tau<n$. Intuitively, overprovision of public goods is possible, because each old member exerts both a positive externality (on his fellow club members and on entrants into his club) and a negative externality (on members of other clubs, by "stealing" new members). Depending on parameters, either effect can dominate.

If $\alpha=1,(11)$ cannot hold, so that the model delivers the standard underprovision result in this case, because each member disregards the effect of his effort on the public good consumption of both the $M-1$ other old members and the $P / n$ new prospective members.

Centralized provision of public goods. Consider now a situation where the ties within a club are strong enough to support a cooperative effort allocation in which all club members choose their effort level so as to maximize the utility of (old) club members. This may be a reasonable assumption for churches deciding on missionary activity and possibly for groups in economics departments trying to attract graduate students to their field. In this scenario, the club maximizes

$$
M\left[\alpha M e+(1-\alpha) P\left(\frac{1}{n}+\frac{M e-\bar{G}}{\tau}\right)-c(e)\right] .
$$

Taking the derivative with respect to $e$ yields

$$
M\left[\alpha M+(1-\alpha) M \frac{P}{\tau}-c^{\prime}(e)\right]=0 .
$$

Comparing (13) with (10), it is clear that more of the public good is provided when the provision decision is made centrally for the club than when members decide individually. Comparing (13) with (7), effort is overprovided relative to the social optimum whenever

$$
(1-\alpha) \frac{M}{\tau}>\frac{1}{n}
$$

Again, the public good is more likely to be overprovided the higher is $n$, and the lower are $\tau$ and $\alpha$ (i.e., the more intense and important is competition for new members). In addition, a higher $M$ makes overprovision more likely, because the positive externality on fellow club members is now completely internalized while the negative externality on members of other clubs continues to be ignored.

Note also that, if the club also internalizes the utility of new members, then overprovision of the public good is guaranteed, because all positive externalities are internalized, while a negative externality exists between different clubs. We summarize the main results.

Proposition 1. 1. If individual club members decide on how much public good to supply, then the equilibrium provision level is higher than socially optimal if inequality (11) holds, and lower than socially optimal if the reverse inequality holds. 
2. If the public good provision decision is centralized within each club, then the equilibrium provision level is higher than in the case of individual provision, and higher than socially optimal if inequality (14) holds, and lower than socially optimal if the reverse inequality holds.

\section{Extensions and applications}

\subsection{Model extensions}

Not all potential new members join. So far, we have assumed that all potential new members will join one of the $n$ available clubs in equilibrium. If $\tau$ is very large (or $A$ is small), then new types whose location is sufficiently far away from the location of the nearest club may choose not to join any club. We now analyze how this changes our results.

Consider a potential new member located at $x \in\left[0, \frac{1}{2 n}\right]$ who is just indifferent between joining club 1 and not joining any club: $A+G_{1}-\tau x=0$. Since all individuals located closer to 0 than this individual join club 1 , the expected number of new club 1 members is

$$
P_{1}=2 P \frac{A+G_{1}}{\tau} .
$$

The social optimization problem is

$$
\max _{e} n M\left[\alpha M e+2(1-\alpha) P \frac{A+G_{1}}{\tau}-c(e)\right]+n\left(2 P \frac{A+G_{1}}{\tau}\right) \frac{A+M e}{2} .
$$

In contrast, if the provision decision is centralized within each club, the club maximizes

$$
\max _{e} n M\left[\alpha M e+2(1-\alpha) P \frac{A+G_{1}}{\tau}-c(e)\right] .
$$

It is immediate from comparing (15) and (16) that the level provided by the clubs is less than the socially optimal level. Furthermore, when the provision decision is made by individual club members, the level supplied is even lower than in the case of centralized provision. Hence we have

Proposition 2. If, in equilibrium, no potential new member type exists that is indifferent between two clubs, then the equilibrium public good provision level is lower than socially optimal. This is true even when the provision decision is centrally coordinated by each club.

The intuitive reason for this result is simple: If clubs effectively do not compete with each other for new members, then they do not impose negative externalities on each other. Rather, the only externality present in this situation is the standard one, neglecting the 
positive effect public goods have on potential new members (and other old club members, if the provision decision is made by individual members). This result therefore shows that the driving force behind any overprovision result in this paper is not the assumption that old members have a preference for attracting new members per se, but rather the combination: Clubs care about new members and compete for them with other clubs.

Direct state provision vs. prizes. Suppose that the equilibrium public good provision level is below the socially optimal level, and consider a social planner who is interested only in increasing the equilibrium level of public good provided. Suppose further that there are two alternative policies that cost the same amount of money, so the question is simply which one is more successful in raising equilibrium public good supply: In the first scenario, the social planner produces an amount $\Delta_{0}$ of the public good in each club and then individuals decide how much to contribute additionally. Another way of thinking about $\Delta_{0}$ is that the social planner supports all providers in a way that shifts their cost function to $c\left(e-\Delta_{0}\right)$. For example, the social planner could give all researchers a course off their teaching load, which allows them to do more research. ${ }^{14}$

In the second scenario, the social planner promises to distribute a "prize" of size $\Pi_{0}$ to one of the clubs, and the probability that a club is awarded the prize is proportional to the number of new members. The idea behind the distribution of a prize is that the social planner uses the decisions of the potential new members to judge the quality of the public good provision of the different clubs. This is particularly useful for providing incentives when the social planner cannot directly observe the quality of the public goods provided by the different clubs. In that case, it would not be possible for the social planner to pay the clubs directly for providing more of their respective public goods.

We assume that the provision decision in each club is centralized and, for tractability, we assume that each club has a quadratic cost function:

$$
u=\alpha(\Delta+e)+(1-\alpha)\left(P\left[\frac{1}{n}+\frac{e-\bar{e}}{\tau}\right]\right)+\left[\frac{1}{n}+\frac{e-\bar{e}}{\tau}\right] \Pi-k e^{2},
$$

where $\Delta$ is the amount of public good provided directly by the social planner, $\Pi$ is the prize money, and the term in square brackets is the probability that the club wins the prize.

The first scenario, direct provision, corresponds to $\Delta=\Delta_{0}, \Pi=0$; and the second, prize, scenario corresponds to $\Delta=0, \Pi=\Pi_{0}$. Differentiating (17) yields

$$
\alpha+\frac{1-\alpha}{\tau} P+\frac{\Pi}{\tau}-2 k e=0
$$

\footnotetext{
${ }^{14}$ Note that it is plausible that, the more clubs there are and therefore, the more different public goods there are, the less $\Delta_{0}$ can be produced in each club for a fixed amount of money; however, for now, we just take $\Delta_{0}$ as exogenous and will return to this issue below.
} 
Solving for $e$, we get

$$
e=\frac{1}{2 k \tau}[\alpha \tau+(1-\alpha) P+\Pi]
$$

Hence, the equilibrium provision level in the first scenario where the planner directly provides $\Delta=\Delta_{0}$, but no prize, is

$$
e_{1}+\Delta_{0}=\frac{1}{2 k \tau}[\alpha \tau+(1-\alpha) P]+\Delta_{0}
$$

In the second (prize) scenario, the public good is only provided by the clubs and equal to

$$
e_{2}=\frac{1}{2 k \tau}\left[\alpha \tau+(1-\alpha) P+\Pi_{0}\right]
$$

The terms in (20) and (21) are equal when

$$
\Delta_{0}^{*}=\frac{\Pi_{0}}{2 k \tau} .
$$

If $\Delta_{0}$ is larger than the critical value $\Delta_{0}^{*}$, then it is optimal for the social planner to provide the public good directly, and if $\Delta_{0}$ is smaller, then it is optimal to donate the prize.

Intuitively, the critical level of directly supplied public good increases with the size of the prize that could be promised alternatively, and decreases with $k$ and $\tau$, because both of these parameters determine how strong the clubs increase their public good supply as a response to the prize money they could win.

More interestingly (and perhaps surprisingly), the critical level does not depend on any of the following: The number of clubs $n$, the number of potential new members $P$, and the parameter $\alpha$ of the utility function.

Independence of $\alpha$ means that, whether the club members are intrinsically motivated by their own public good consumption or by the prospect of attracting new members, does not matter for whether direct provision or the donation of prizes is more effective for the social planner to bring about an increase in the public good level.

Note that an increase in $n$ does not reduce the effectiveness of a given prize to motivate clubs. While a higher $n$ decreases the likelihood of winning for each club, the marginal effect of effort on that probability stays the same, independent of $n$. On the other hand, it appears reasonable to assume that the amount $\Delta_{0}$ of the public goods that can be produced by the social planner for the same amount of money decreases, when $n$ increases. If so, then the more different clubs there are, the more likely it is that a prize is the better instrument for increasing public good supply.

\subsection{Applications}

Competing through infrastructure. In the location decisions of firms and individuals, the "quality of life" in a particular city often plays a very important role. Conversely, 
cities often try actively to influence these decisions by providing or subsidizing public goods like sports teams, symphony orchestras or museums, in order to attract businesses or highly-skilled individuals to their city. For example, when a city considers whether to build a new sports stadium, an often used argument is that this will attract new businesses, providing significant indirect economic benefits. Note, however, that these benefits for the city often correspond to losses of a similar size for another city in which those firms would locate in the absence of a new stadium.

Following the local public goods literature pioneered by Tiebout (1956), assume that each city chooses its provision of public goods internalizing the benefits of its current residents from the public good (so that we are in the centralized provision scenario of the model). From equation (14), we know that overprovision relative to the social optimum becomes more likely if the weight $(1-\alpha)$ attached to attracting new businesses is high. Note that we can, in principle, draw some conclusions about the size of $\alpha$ from the value that is attached to attracting new businesses in the cost-benefit analysis of a project.

Overprovision also becomes more likely if the mobility of firms increases (i.e., a lower $\tau)$. For example, this might be the case if new information technology like the internet allows firms to locate farther away from their customers, or if more firms are "knowledgebased" (i.e., don't have to transfer large production facilities if they want to change their location). In this context, it is interesting to note that there was a large increase in stadium construction in the 1990es. While this is just a suggestive story, it is at least consistent with our model. ${ }^{15}$

If cities compete fiercely against each other to attract businesses through their public good provision, then our model implies that the state or federal government should not subsidize such projects, but rather tax or discourage them. This is particularly true if a large portion of the benefit attributed to the project relates to this motivation.

Also note that competing for businesses through public good provision has the potential of creating worse welfare effects than competing through direct subsidies paid for firms choosing their location: Suppose, for simplicity, that $\alpha=0$ (i.e., the public good has no value per se for the cities' original inhabitants). If firms are sufficiently flexible ( $\tau$ is low), then the public good is overprovided in our model, which means intuitively that the last unit of the public good (costing one dollar to the city's inhabitants) is valued at less than a dollar by the firms.

Alternatively, consider what happens if cities compete by offering direct subsidies to firms. Effectively, this is a Salop (1979) oligopoly model with negative "production costs" (as cities place a positive value when firms locate there), and the equilibrium subsidy paid is equal to the cities' valuation of a firm minus the "transportation cost" to the next city.

\footnotetext{
${ }^{15}$ We are grateful to Brad Humphreys for suggesting this example.
} 
Note that this subsidy is just a transfer from cities to firms, and hence does not affect social welfare.

Sports competitions. Consider a setting in which individual athletes ("old members", in the language of our model) compete for the appreciation of spectators ("potential new members"). Spectators are more likely to prefer more successful athletes (though other factors such as geography, personality etc. will also play a role). Furthermore, it appears plausible that the overall level of performance has only a minor influence on the spectators' utility, at least on the margin: Whether the Olympic gold medalist wins the Marathon race in 2:35 (as in 1948) or in 2:10 (2000) probably has no significant effect on how much the respective spectators enjoyed the race or on how much they appreciated the winner.

Hence, in sports, the negative externality of athletes on each other is likely to outweigh the (small, if any) positive effect of a higher performance level on spectators' utility. Thus, from a social point of view, "effort" to win should be discouraged or at least not be particularly encouraged (at the margin). Indeed, certain performance-enhancing substances are banned as doping in most sports, and the Olympics had a long history of banning "professional" athletes (who could presumably exert more effort than amateurs). ${ }^{16}$

Warfare. In warfare, soldiers often voluntarily provide public goods (e.g., fight bravely, not surrender in spite of enemy superiority) in a way that is inconsistent with the view that they are motivated by their role as "consumers" of the military outcome of the war; in wars between large societies, individual lower ranked soldiers are extremely unlikely to influence the outcome of the conflict even with very brave actions.

Recognition by their countrymen as heroes appears to be a very important stimulus for soldiers (and probably more important than monetary incentives, at least for a significant fraction of soldiers). Again, there exists a negative externality among soldiers vying for recognition, but in this field, the positive externality for the whole country (through more successful warfare) is probably much more important. This is true because, different from our model, in warfare not only that fraction of the general population which chooses to honor a particular hero benefits from his actions, but rather the public goods provided by all soldiers benefit all citizens of the country.

To induce more courageous fighting, the military often provides medals for those fighters who provide the most successful endeavors for the public good. In terms of our model, one can interpret the institution of medals as one that lowers $\tau$ : A medal makes it possible for people who are "further away" from the soldier to recognize (and honor) him as hero. Institutions that lower $\tau$ and thereby increase the equilibrium level of public good

\footnotetext{
${ }^{16}$ The problem with the latter policy was that it was hard to implement consistently.
} 
provision (cf. equation (10)) are useful in settings where the public good is underprovided in equilibrium.

Researchers. One of the principal motivations for researchers is the recognition of their peers. They care about the dissemination of their ideas and possibly also about their own reputation. In terms of our model, think of the act of conducting and publishing research as public good provision by $n$ "clubs" with one member each (or several members, for coauthored papers). Each of these clubs is endowed with an "idea" that can be developed into a published paper. The "potential new members" are other researchers who choose which papers to read. ${ }^{17}$ The effort that goes into the development and presentation of the idea increases its value to other researchers, and better developed ideas attract more readers and more praise. On the other hand, at least the quality of the presentation hardly provides any direct utility for the researcher, so $\alpha$ can be assumed to be close to zero.

From (11), after substituting $\alpha=0$ and rearranging, we find that researchers underprovide effort to develop their ideas if $\tau>n$, and they overprovide effort when this inequality is reversed. Hence, underprovision is more likely the higher is $\tau$, i.e. the less inclined professional readers are to read articles outside their core area of interest. In economics, $\tau$ appears to be relatively low compared to, say, mathematics or the sciences, and so economists tend to spend a lot more effort on writing introductions that are accessible to fellow economists outside their narrow area of specialization than those other disciplines.

\section{Conclusion}

This paper proposes a model of public good provision by clubs in which public good providers are motivated by the hope of gaining the respect of their audience (or making audience members join their club). We argue that this incentive has the potential of explaining many of the most important cases in which public goods are privately provided. Competition for new members (or audience approval) generates an additional, negative externality between different clubs. It is possible that this negative externality outweighs the standard positive one, in which case the public good supply by private providers can be higher than socially optimal.

\footnotetext{
${ }^{17}$ In this respect, it does not matter that some researchers, as consumers, may choose to read several papers, as long as the quantity of papers that each researcher reads is fixed.
} 


\section{References}

Andreoni, J. (1989). Giving with impure altruism: Applications to charity and Ricardian equivalence. Journal of Political Economy 97(6), 1447-1458.

Andreoni, J. (1990). Impure altruism and donations to public goods: A theory of warmglow giving? Economic Journal 100(401), 464-77.

Becker, G. S. (1974). A theory of social interactions. Journal of Political Economy 82(6), 1063-93.

Benabou, R. and J. Tirole (2006). Incentives for pro-social behavior. American Economic Review 96(5), 1652-1678.

Bergstrom, T., L. Blume, and H. Varian (1986). On the private provision of public goods. Journal of Public Economics 29(1), 25-49.

Blumkin, T. and E. Sadka (2006). On the desirability of taxing charitable contributions. Tel Aviv University, mimeo.

Buchanan, J. M. (1965). An economic theory of clubs. Economica 32, 1-14.

Giles, J. (2005). Internet encyclopaedias go head to head. Nature 438, 900-901. Posted December 14, 2005.

Glazer, A. and K. A. Konrad (1996). A signaling explanation for charity. American Economic Review 86(4), 1019-28.

Perens, B. (2005). The emerging economic paradigm of open source. http://perens.com/Articles/Economic.html.

Peters, M. and A. Siow (2002). Competing premarital investments. Journal of Political Economy 110, 592-608.

Salop, S. C. (1979). Monopolistic competition with outside goods. Bell Journal of Economics 10(1), 141-156.

Scotchmer, S. (2002). Local public goods and clubs, Volume 4, Chapter 29, pp. 19972042. Elsevier.

Tiebout, C. M. (1956). A pure theory of local expenditures. Journal of Political Economy $64,416-424$. 


\section{CESifo Working Paper Series}

(for full list see www.cesifo-group.de)

1860 Marcel Gérard, Reforming the Taxation of Multijurisdictional Enterprises in Europe, "Coopetition" in a Bottom-up Federation, November 2006

1861 Frank Blasch and Alfons J. Weichenrieder, When Taxation Changes the Course of the Year - Fiscal Year Adjustments and the German Tax Reform 2000/2001, November 2006

1862 Hans Jarle Kind, Tore Nilssen and Lars Sørgard, Competition for Viewers and Advertisers in a TV Oligopoly, November 2006

1863 Bart Cockx, Stéphane Robin and Christian Goebel, Income Support Policies for PartTime Workers: A Stepping-Stone to Regular Jobs? An Application to Young LongTerm Unemployed Women in Belgium, December 2006

1864 Sascha O. Becker and Marc-Andreas Muendler, The Effect of FDI on Job Separation, December 2006

1865 Christos Kotsogiannis and Robert Schwager, Fiscal Equalization and Yardstick Competition, December 2006

1866 Mikael Carlsson, Stefan Eriksson and Nils Gottfries, Testing Theories of Job Creation: Does Supply Create Its Own Demand?, December 2006

1867 Jacques H. Drèze, Charles Figuières and Jean Hindriks, Voluntary Matching Grants Can Forestall Social Dumping, December 2006

1868 Thomas Eichner and Marco Runkel, Corporate Income Taxation of Multinationals and Unemployment, December 2006

1869 Balázs Égert, Central Bank Interventions, Communication and Interest Rate Policy in Emerging European Economies, December 2006

1870 John Geweke, Joel Horowitz and M. Hashem Pesaran, Econometrics: A Bird's Eye View, December 2006

1871 Hans Jarle Kind, Marko Koethenbuerger and Guttorm Schjelderup, Taxation in TwoSided Markets, December 2006

1872 Hans Gersbach and Bernhard Pachl, Cake Division by Majority Decision, December 2006

1873 Gunther Schnabl, The Evolution of the East Asian Currency Baskets - Still Undisclosed and Changing, December 2006 
1874 Horst Raff and Michael J. Ryan, Firm-Specific Characteristics and the Timing of Foreign Direct Investment Projects, December 2006

1875 Jukka Pirttilä and Håkan Selin, How Successful is the Dual Income Tax? Evidence from the Finnish Tax Reform of 1993, December 2006

1876 Agnieszka Stążka, Sources of Real Exchange Rate Fluctuations in Central and Eastern Europe - Temporary or Permanent?, December 2006

1877 Xavier Calsamiglia, Teresa Garcia-Milà and Therese J. McGuire, Why do Differences in the Degree of Fiscal Decentralization Endure?, December 2006

1878 Natacha Gilson, How to be Well Shod to Absorb Shocks? Shock Synchronization and Joining the Euro Zone, December 2006

1879 Scott Alan Carson, Modern Health Standards for Peoples of the Past: Biological Conditions by Race in the American South, 1873 - 1919, December 2006

1880 Peter Huber, Michael Pfaffermayr and Yvonne Wolfmayr, Are there Border Effects in the EU Wage Function?, December 2006

1881 Harry Flam and Håkan Nordström, Euro Effects on the Intensive and Extensive Margins of Trade, December 2006

1882 Panu Poutvaara and Mikael Priks, Hooliganism in the Shadow of the 9/11 Terrorist Attack and the Tsunami: Do Police Reduce Group Violence?, December 2006

1883 Ruud A. de Mooij and Gaëtan Nicodème, Corporate Tax Policy, Entrepreneurship and Incorporation in the EU, December 2006

1884 Johannes Becker and Clemens Fuest, Corporate Tax Policy and International Mergers and Acquisitions - Is the Tax Exemption System Superior?, January 2007

1885 Momi Dahan and Udi Nisan, The Effect of Benefits Level on Take-up Rates: Evidence from a Natural Experiment, January 2007

1886 José García-Solanes, Francisco I. Sancho-Portero and Fernando Torrejón-Flores, Beyond the Salassa-Samuelson Effect in some New Member States of the European Union, January 2007

1887 Peter Egger, Wolfgang Eggert and Hannes Winner, Saving Taxes Through Foreign Plant Ownership, January 2007

1888 Timothy J. Goodspeed and Andrew Haughwout, On the Optimal Design of Disaster Insurance in a Federation, January 2007

1889 Wim Groot, Henriëtte Maassen van den Brink and Bernard van Praag, The Compensating Income Variation of Social Capital, January 2007 
1890 Bas Jacobs, Ruud A. de Mooij and Kees Folmer, Analyzing a Flat Income Tax in the Netherlands, January 2007

1891 Hans Jarle Kind, Guttorm Schjelderup and Frank Stähler, Newspapers and Advertising: The Effects of Ad-Valorem Taxation under Duopoly, January 2007

1892 Erkki Koskela and Rune Stenbacka, Equilibrium Unemployment with Outsourcing under Labour Market Imperfections, January 2007

1893 Maarten Bosker, Steven Brakman, Harry Garretsen, Herman de Jong and Marc Schramm, The Development of Cities in Italy 1300 - 1861, January 2007

1894 Michel Beine, Oscar Bernal, Jean-Yves Gnabo and Christelle Lecourt, Intervention Policy of the BoJ: A Unified Approach, January 2007

1895 Robert S. Chirinko and Daniel J. Wilson, State Investment Tax Incentives: A Zero-Sum Game?, January 2007

1896 Theo S. Eicher and Oliver Roehn, Sources of the German Productivity Demise Tracing the Effects of Industry-Level ICT Investment, January 2007

1897 Helge Berger, Volker Nitsch and Tonny Lybek, Central Bank Boards around the World: Why does Membership Size Differ?, January 2007

1898 Gabriel Felbermayr and Wilhelm Kohler, Does WTO Membership Make a Difference at the Extensive Margin of World Trade?, January 2007

1899 Benno Torgler and Friedrich Schneider, The Impact of Tax Morale and Institutional Quality on the Shadow Economy, January 2007

1900 Tomer Blumkin and Efraim Sadka, On the Desirability of Taxing Charitable Contributions, January 2007

1901 Frederick van der Ploeg and Reinhilde Veugelers, Higher Education Reform and the Renewed Lisbon Strategy: Role of Member States and the European Commission, January 2007

1902 John Lewis, Hitting and Hoping? Meeting the Exchange Rate and Inflation Criteria during a Period of Nominal Convergence, January 2007

1903 Torben M. Andersen, The Scandinavian Model - Prospects and Challenges, January 2007

1904 Stephane Dees, Sean Holly, M. Hashem Pesaran and L. Vanessa Smith, Long Run Macroeconomic Relations in the Global Economy, January 2007

1905 Richard Jong-A-Pin and Jakob De Haan, Political Regime Change, Economic Reform and Growth Accelerations, January 2007 
1906 Sascha O. Becker and Peter H. Egger, Endogenous Product versus Process Innovation and a Firm's Propensity to Export, February 2007

1907 Theo S. Eicher, Chris Papageorgiou and Oliver Roehn, Unraveling the Fortunates of the Fortunate: An Iterative Bayesian Model Averaging (IBMA) Approach, February 2007

1908 Liliana E. Pezzin, Robert A. Pollak and Barbara S. Schone, Efficiency in Family Bargaining: Living Arrangements and Caregiving Decisions of Adult Children and Disabled Elderly Parents, February 2007

1909 Christian Keuschnigg and Soren Bo Nielsen, Self-Selection and Advice in Venture Capital Finance, February 2007

1910 Rune Jansen Hagen and Gaute Torsvik, Irreversible Investments, Dynamic Inconsistency and Policy Convergence, February 2007

1911 Eric A. Hanushek and Ludger Woessmann, The Role of School Improvement in Economic Development, February 2007

1912 Bernard M. S. van Praag, Perspectives from the Happiness Literature and the Role of New Instruments for Policy Analysis, February 2007

1913 Volker Grossmann and Thomas M. Steger, Growth, Development, and Technological Change, February 2007

1914 Margarita Katsimi and Thomas Moutos, Human Capital and the Feldstein-Horioka Puzzle, February 2007

1915 Oliver Roehn, Theo S. Eicher and Thomas Strobel, The Ifo Industry Growth Accounting Database, February 2007

1916 Ian Babetskii, Aggregate Wage Flexibility in Selected New EU Member States, February 2007

1917 Burkhard Heer, Alfred Maussner and Paul D. McNelis, The Money-Age Distribution: Empirical Facts and Limited Monetary Models, February 2007

1918 Yin-Wong Cheung, Menzie D. Chinn and Eijii Fujii, The Overvaluation of Renminbi Undervaluation, February 2007

1919 Jim Malley, Apostolis Philippopoulos and Ulrich Woitek, To React or Not? Fiscal Policy, Volatility and Welfare in the EU-3, February 2007

1920 Mattias Polborn, Competing for Recognition through Public Good Provision, February 2007 